\title{
Identification of instability in natural rubber prices in Sri Lanka
}

\author{
H M L K Herath*, S Samita** and Wasana Wijesuriya*** \\ * Dept. of Agri-Business Management, Faculty of Agriculture and Plantation Management, \\ Wayamba University of Sri Lanka, Makandura, Gonawila \\ ** Dept. of Crop Science, Faculty of Agriculture, University of Peradeniya, Peradeniya \\ *** Biometry Section, Rubber Research Institute of Sri Lanka, Dartonfield, Agalawatta
}

Received: 28 November 2013

\begin{abstract}
Instability of Natural Rubber (NR) prices is a key economic issue in the NR industry. A few studies have been conducted to investigate this issue especially giving more attention on the seasonal variations in NR prices. However, a little attention has been paid on studying the changes in long term trend and volatility in NR prices. Consequently, this study aims to undertake an in-depth analysis on the instability of NR prices giving more emphasis on both short run and long run price variations. During this study, we recognized that the long term price trends succumb to frequent changes that affect long term investments and the policy setup in the NR industry. Stochastic volatility of random shocks in RSS prices was identified as a serious issue which especially affects the rubber smallholder sector. Further, it was noticed that the usual seasonal variations in NR prices are overwhelmed by the frequent changes in long term trends and random shocks of NR prices. Moreover, we identified that seasonal stochastic time series models are more efficient than the decomposition time series techniques for modeling NR prices in the presence of the above mentioned issues persistent in NR price series.
\end{abstract}

Key words: decomposition techniques, natural rubber, price instability, SARIMA

\section{Introduction}

It is a common phenomenon that developing countries are dependent on export earnings through a few commodities of which majority are of primary in nature. Hence, the impact of price instability of primary commodities on the economy of such nations is substantial. Out of a few export oriented commodities, rubber plays an important role in Sri Lankan economy which is exported either in the form of a raw material or a value added product. Samarappuli (1993) reported that price 
instability is one of the key issues in the Natural Rubber (NR) sector which is believed to be persisting. If NR price instability continues, then it will be critical to the growth of overall economy of the country. It can be noticed that this consequence is common even for major NR producing countries such as Thailand, Malaysia and Philippines (Chang, 2010; Sang, 2013). Presently, in local context, it can be noticed that the conventional export oriented NR market has shifted to a new market focused on NR based value added product manufacture. Further, even though present NR prices seems to be very attractive compared to nominal prices observed during last few decades, it could be completely different with respect to their real prices.

The behavior of prices of different NR grades has been studied by Wijesuriya et al. (1995) identifying their trends and the seasonal variations. Wijesuriya and Thattil (1996) have established the relationships between seasonal variations of average NR auction prices and production, consumption and stocks of NR. Edirisinghe and Herath (2004) have further investigated the seasonal behavior of NR prices of Sri Lanka and some of the international markets by employing the decomposition time series methods. The price instability is not only coupled with the seasonal variations in price but also heavily associated with the changes in long term price trend and price volatility. Moreover, stochastic volatility in returns of prices is identified as the risk premium associated with the prices. However, none of the studies has investigated the changes in the trends and the volatility of prices. Samarappuli (1993) suggested the need of an indepth analysis of instability on NR prices while there is no study reported on analysis of NR prices since the recovery of the NR sector from its serious depression experienced during early 2000s in Sri Lanka.

There are many studies carried out to investigate the NR price instability with respect to changes in the conditional mean and the variance of NR prices in other international markets employing appropriate theoretically sound methodologies. Daud (1983), Shamsudin and Fathima (1990), Romprasert (2009) and Chinye and Mesike (2012) have applied ARIMA models to forecast NR prices successfully in forecasting when it was compared to the conventional smoothing time series techniques. Sang et al. (2013) have used a vector autoregressive moving average model together with a generalized autoregressive conditionally heteroschedastic model (VARMA-GARCH) model to study the behavior of conditional mean and the volatility of NR prices. Moreover, Arumugam and Anithakumari (2013) have used a Seasonal Autoregressive Moving Average model to identify seasonal variation in NR production in India. With this background, this study was done to identify the instability of NR 
H M L K Herath et al.

prices in the local market using appropriate time series methods.

\section{Materials and Methods}

Data: Monthly Colombo auction prices of different grades of Ribbed Smoked Sheets (RSS), namely RSS1-RSS5 and different Latex Crepe (LC) grades, namely LC1X and LC1-LC4 form 1985 to 2012 were used in the analysis, which are available in the database maintained by the Biometry Section of Rubber Research Institute of Sri Lanka. RSS is the main product of the smallholder rubber sector while LC is the main product of the rubber estate sector.

Analysis: Nominal rubber prices were converted into real prices to avoid impacts due to rising inflation. Colombo Consumers Price Index (CCPI) was used as the deflator to convert prices. Suppose nominal price at time $t$ is $p_{n t}$ and real price at time $t$ is $p_{r t}$, where $t=$ $1,2, \ldots . T$. Then, $p_{r t}=p_{n t} \times I C C P I_{t}$, where $I C C P I_{t}=\frac{C C P I_{t}}{C C P I_{T}}$ which is the ratio between CCPI at time $t$ and CCPI at time $T$ (last value of CCPI in the series). Both nominal and real price series of each grade of RSS and LC were compared to understand if any apparent behavioral changes in time were apparent. However, we have used real prices in model fitting and identification of the instability of the prices.

Price variations can be recognized in different forms viz. trend, seasonal and the random variations. Change in the conditional mean over different periods of time can be regarded as the instability of price in the long run which is actually the change in the price trend. Seasonal variations are some systematic behaviors of prices observed within a given time frame (e.g. within a year). Random variation of price at a given time $t,\left(r_{t}\right)$ is thought of as the risk associated with the price in the short run. If the random variability is constant and predictable, then prices cannot be considered as unstable. However if the random variability is changing and unpredictable, then it can be recognized as the instability. Thus, Short run price instability can be defined as the stochastic volatility in the innovations (random variations) of prices which is the most serious and given more emphasis during the analysis of this study.

It is customary to check the stationarity of time series prior to fitting an appropriate model for which Augmented Dickey Fuller (DF) test (Dickey and Fuller, 1981) was used in this study. Different model types such as decomposition models and stochastic models were used to identify and verify the variability in NR prices due to different components viz. trend, seasonal and random component. The additive decomposition model is illustrated in equation 1 while the multiplicative model is illustrated in equation 2. Different models including loess smoothing (Cleveland, 1990) were also employed to estimate the trend component.

$y_{t}=T_{t}+S_{t}+E_{t}$ 
$y_{t}=T_{t} S_{t} E_{t}$

Where,

$$
\begin{aligned}
& y_{t} \text { - Price in time } t, \\
& T_{t}-\text { Trend component in time } t, \\
& S_{t}-\text { Seasonal component in } \\
& \quad \text { time } t, \\
& E_{t} \text { - Error component in time } t
\end{aligned}
$$

A multiplicative Seasonal Autoregressive Integrated Moving Average model, $\operatorname{SARIMA}(p, d, q) \times(P, D, Q)$ (Box et al., 1998) was employed as the stochastic model which is illustrated in equation 3 .

$\Phi_{P}\left(B^{s}\right) \phi(B) \nabla_{s}^{D} \nabla^{d} y_{t}=\alpha+$ $\Theta_{Q}\left(B^{S}\right) \theta(B) w_{t}$

$\phi(B)$ and $\theta(B)$ are the autoregressive and moving average operators respectively of orders $p$ and $q . \Phi_{P}\left(B^{S}\right)$ and $\Theta_{Q}\left(B^{S}\right)$ are respectively seasonal autoregressive and moving average components of order $P$ and $Q . \nabla^{d}=(1-B)^{d}$ is the ordinary differencing component while $\nabla_{s}^{D}=\left(1-B^{S}\right)^{D}$ is the seasonal differencing component. Reason for using both decomposition models and a stochastic model was to verify the identified instability by one model over the other model.

Initial identification of different model types was based on the respective time series plots, Autocorrelation Functions $(A C F)$ and Partial Autocorrelation Functions $(P A C F)$. Testing goodness of fit of decomposition models was carried out employing some commonly used goodness of fit criteria based on the forecasting efficiency viz. Mean Squared Deviation (MSD), Mean Absolute Error $(M A E)$ and Mean Absolute Percentage Error (MAPE). In addition to the criteria mentioned above, $A I C$ and BIC were used to test the goodness of fit of stochastic models.

We used two commonly found tests, namely Engle's LM test (Engle, 1982) and McLeod-Li test McLeod and LI (1983) for testing the stochastic volatility of the innovations from different models fitted to real prices of different NR grades. Although Engle's LM test originally developed for testing ARCH effects, Bollerslev (1986) confirmed that it is efficient in detecting GARCH disturbances as well. McLeodLi test identifies any significant serial dependencies in the pre whitened and squared series.

\section{Results and Discussion}

Time series plots of nominal and real prices of LC-1X and RSS 1 are depicted in Figure 1. Although it is claimed that there is an inherent instability of natural rubber prices, it is not clearly visible in observed prices (nominal prices) which is indicated by the apparent trend present in the nominal price series depicted in the Figure 1. However, it can be noticed that the continuing trend in nominal prices is not shown in the real price series of LC and RSS grades. It is clear that the trends in prices are due to the effect of rising inflation persisting in the Sri Lankan economy. 
Thus the real prices should be investigated to understand if there exists instability in NR prices. The depressions of NR prices prevailed during the period of 1998-2004 and world economic crisis in 2008 can be identified in the real price series. Further, it was noticed a similar pattern as depicted in the Figure 1 in nominal and real prices of other LC and RSS grades.

Correlation matrices of different RSS grades and LC grades are given in
Figure 2 of which all correlation coefficients were statistically highly significant. It can be noticed that real prices of other RSS grades are highly correlated with real prices of RSS1 which indicate that behavior of the other RSS grades are similar to the behavior of RSS1 depicted in Figure 1A. Similarly, other LC grades are highly correlated with LC-1X ensuring that they also behave as similarly as LC-1X behaves (Fig. 1B).

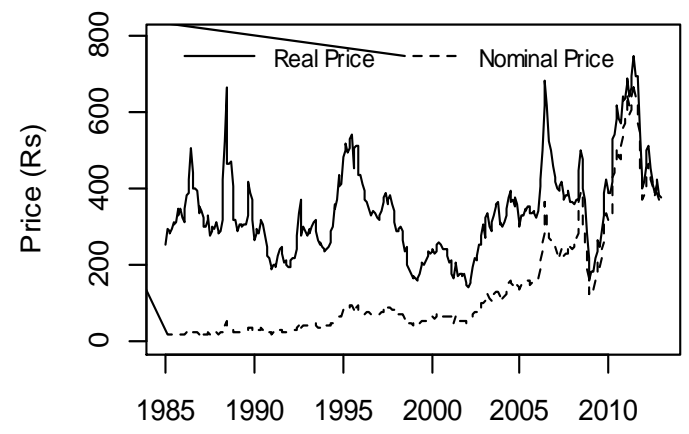

(a)

Time (Months-Years)

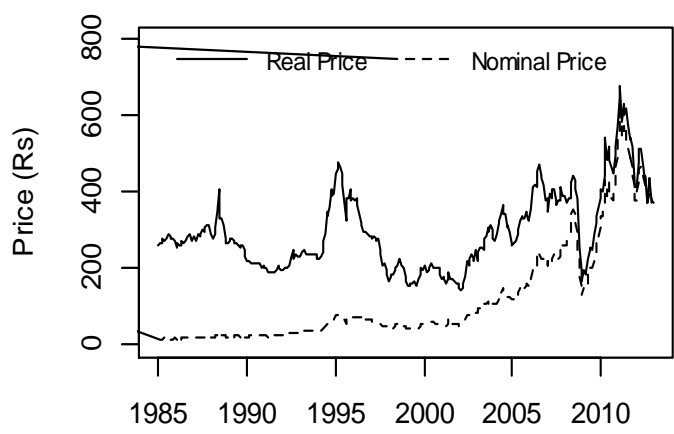

(b)

Time (Months-Years)

Fig. 1. Monthly nominal and real price time series of (a) LC-1Xand (b) RSS1 for the time period from 1985 to 2012

\begin{tabular}{|c|c|c|c|c|c|c|c|c|c|}
\hline & $\mathrm{DSC} 1$ & $\begin{array}{c}\text { A } \\
\text { DCS? }\end{array}$ & $\mathrm{PCC}_{3}$ & PSC4 & & $1 \mathrm{Y}$ & B & IC? & $\mathrm{I}_{C}{ }_{3}$ \\
\hline & & & & & & & & & \\
\hline RSS2 & 0.997 & & & & LC-1 & 0.999 & & & \\
\hline RSS3 & 0.995 & 0.997 & & & LC-2 & 0.989 & 0.993 & & \\
\hline RSS4 & 0.995 & 0.995 & 0.995 & & LC-3 & 0.968 & 0.975 & 0.991 & \\
\hline RSS5 & 0.993 & 0.993 & 0.992 & 0.996 & LC-4 & 0.915 & 0.921 & 0.939 & 0.96 \\
\hline
\end{tabular}

Fig. 2. Correlation matrices; A-correlation matrix of different RSS grads, B-correlation matrix of different LC grades 
Results of the augmented Dickey Fuller test applied on real prices of different LC and RSS grades are given in Table 1. It can be noticed that none of the real price series were stationary. The time series plots also suggested that there was some form of a nonlinear trend present in the real price series of the rubber grades under investigation. $A C F \mathrm{~s}$ and $P A C F \mathrm{~s}$ of RSS and LC series indicated that the trend and seasonal components are present in the respective prices, which have been identified earlier by Wijesuriya \& Thattil (1996) and Edirisinhe \& Herath (2004) which was accounted during initial model identification.

Goodness of fit of the selected models is given in Table 2. The multiplicative decomposition model for all rubber grades reported the least MAPE, MAD and MSD of which the numbers are provided in Table 2. The trend component of this model was obtained by loess smoothing. None of the other methods of trend fitting provided such a goodness of fit as of the selected models.

Although significant serial dependencies were apparent in respective ACFs and $\mathrm{PACF}$, it was very difficult to identify exact orders of ordinary and seasonal components in SARIMA model. Because, they were quite different from the theoretical ACFs and PACFs. Thus the best SARIMA model for each rubber grade was selected based on the least AIC. Consequently, SARIMA $(2,1,2)(0,0,1)^{12}$ was identified as the best fitted model for RSS1 while SARIMA $(2,1,2)$ $(1,0,1)^{12}$ was the best fitted model for other RSS grades. For all the LC grades, SARIMA $\quad(0,1,1) \quad(1,0,1)^{12} \quad$ was recognized as the best candidate model. As given in Table 2, it can be noticed that SARIMA models report low figures for respective goodness of fit criteria compared to that of best fitted decomposition models among other decomposition models tested during the analysis. However they cannot be compared based on AIC since AIC cannot be computed for decomposition models. We didn't report the model coefficients of the selected SARIMA models since our scope in this study was to investigate the innovations of these models. However, the model parameters were observed acceptably statistically significant.

Table 1. Results of the augmented Dickey Fuller test on real prices of different NR grades

\begin{tabular}{lccccc}
\hline & Latex Crepe (LC) & \multicolumn{3}{c}{ Ribbed Smoke Sheets (RSS) } \\
\hline Grade & Dickey-Fuller* & p-value & Grade & Dickey-Fuller* & p-value \\
\hline CL-1X & -3.24 & 0.081 & RSS1 & -2.59 & 0.328 \\
LC-1 & -3.26 & 0.078 & RSS2 & -2.65 & 0.301 \\
LC-2 & -3.27 & 0.076 & RSS3 & -2.60 & 0.324 \\
LC-3 & -3.30 & 0.072 & RSS4 & -2.57 & 0.334 \\
LC-4 & -2.94 & 0.181 & RSS5 & -2.62 & 0.316 \\
\hline \multicolumn{2}{r}{$* H_{0}$ :Time series in non-stationary, $n=336$, Lag order=6 and $\alpha=0.05$}
\end{tabular}

42 
H M L K Herath et al.

Table 2. Goodness of fit of the selected models for identifying dynamic behavior of NR prices

\begin{tabular}{|c|c|c|c|c|c|c|c|}
\hline \multirow[t]{2}{*}{ Grade } & \multicolumn{3}{|c|}{$\begin{array}{c}{ }^{1} \text { Goodness of fit of } \\
\text { Decomposition model }\end{array}$} & \multicolumn{4}{|c|}{ Goodness of fit of SARIMA model } \\
\hline & MAPE & MAD & MSD & MAPE & MAD & MSD & AIC \\
\hline RSS1 & 0.101 & 29.46 & 1894.5 & 0.049 & 15.28 & 546.8 & 3097.8 \\
\hline RSS2 & 0.101 & 28.88 & 1823.3 & 0.049 & 14.89 & 526.4 & 3089.5 \\
\hline RSS3 & 0.104 & 28.67 & 1784.9 & 0.051 & 15.00 & 566.7 & 3111.4 \\
\hline RSS4 & 0.108 & 29.13 & 1798.7 & 0.051 & 14.32 & 462.7 & 3041.7 \\
\hline RSS5 & 0.108 & 28.55 & 1762.6 & 0.053 & 14.93 & 500.7 & 3068.2 \\
\hline LC-1X & 0.153 & 50.18 & 4181.3 & 0.063 & 21.84 & 1044.8 & 3322.6 \\
\hline LC-1 & 0.154 & 49.34 & 4076.3 & 0.064 & 21.80 & 1025.8 & 3315.1 \\
\hline LC-2 & 0.157 & 47.58 & 3808.7 & 0.067 & 21.53 & 942.8 & 3284.1 \\
\hline LC-3 & 0.152 & 43.71 & 3270.7 & 0.065 & 19.69 & 812.6 & 3231.9 \\
\hline LC-4 & 0.129 & 33.69 & 2207.1 & 0.060 & 16.56 & 607.6 & 3127.1 \\
\hline
\end{tabular}

${ }^{1}$ Multiplicative decomposition model where trend was estimated by loess smoothing

Instability of $N R$ prices:

Time series plots of innovations of NR prices of RSS1 and LC-1X resulted from both decomposition and SARIMA models are depicted in Figure 3. As depicted in Figure 3b, innovations from the stochastic model fitted to RSS1 and LC-1X clearly show volatility clustering at different time intervals. Since other rubber grades are highly correlated with their superior grade, the same phenomenon can be expected with respect to the other NR grades and it was evident by investigating the respective time series plots. However, volatility clustering was not apparent in the innovations from the decomposition models fitted to RSS1 and LC-1X (Fig. 3a).
Results of the Engle's LM test and McLeod $\mathrm{Li}$ test for ARCH/GARCH effects (stochastic volatility) which were applied to the innovations of two model types fitted to real prices of different NR grades are present in Table 3. For all rubber grades, it can be noticed that both tests have given statistically significant results rejecting the null hypothesis of "no ARCH/GARCH effect". That means regardless of the model type, the innovations of the fitted model to each NR grade are suffering from the stochastic volatility. Consequently the variability associated with real prices of RSS and LC grades change in time which indicates that real prices of both RSS and LC grades are unstable. 

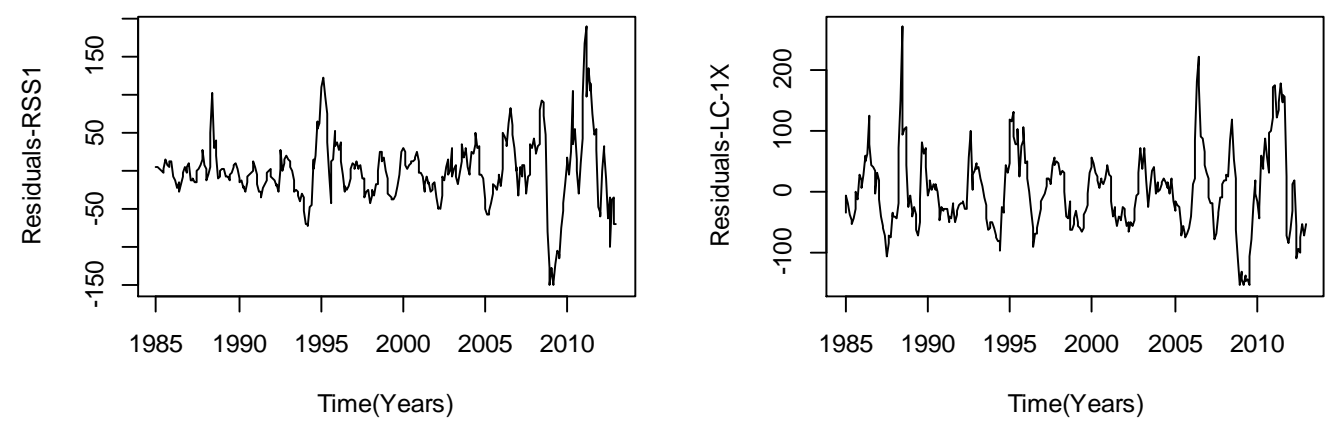

(a) Innovations resulted from the decomposition model
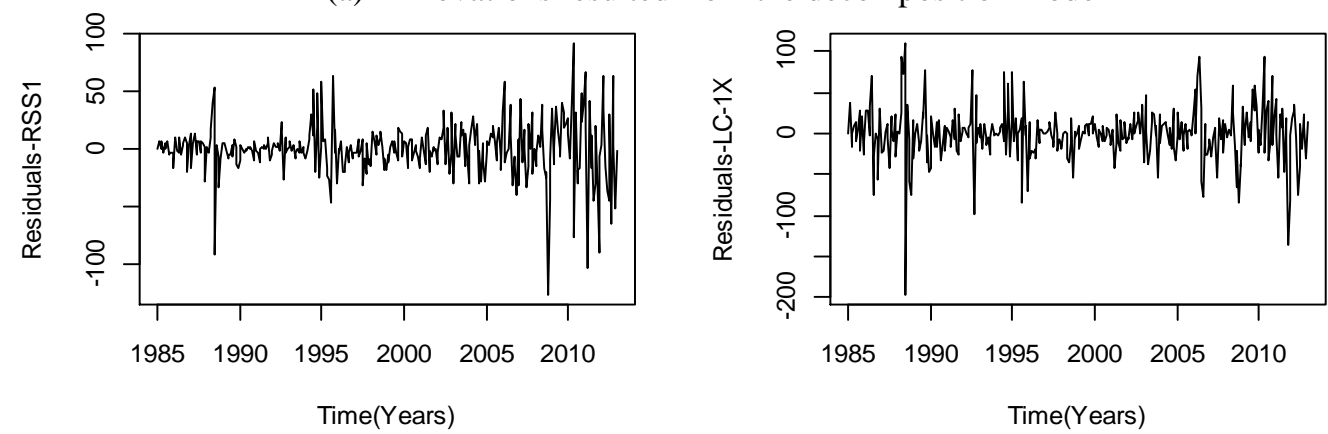

(b) Iinnovations resulted from the stochastic model

Fig. 3. Time series plots of innovations of RSS1 and CL-1X prices resulted from both decomposition and stochastic models

Table 3. Results of the Engle's LM test and McLeod Li test for ARCH/GARCH effects in the innovations from best fitted models on the prices of different NR grades

\begin{tabular}{clccc}
\hline \multirow{2}{*}{ Rubber grade } & \multicolumn{2}{c}{ 'Decomposition model } & \multicolumn{2}{c}{ Stochastic model (SARIMA) } \\
\cline { 2 - 5 } & LM test & McLeod-Li test & LM test & McLeod-Li test \\
\hline RSS1 & $205.09^{* *}$ & $229.82^{* *}$ & $19.57^{*}$ & $71.69^{* *}$ \\
RSS2 & $212.19^{* *}$ & $228.35^{* *}$ & $29.77^{* *}$ & $62.34^{* *}$ \\
RSS3 & $201.29^{* *}$ & $219.42^{* *}$ & $18.43^{*}$ & $39.42^{* *}$ \\
RSS4 & $214.13^{* *}$ & $234.28^{* *}$ & $15.24^{*}$ & $65.26^{* *}$ \\
RSS5 & $205.15^{* *}$ & $222.79^{* *}$ & $18.44^{*}$ & $60.22^{* *}$ \\
LC-1x & $144.92^{* *}$ & $165.15^{* *}$ & $32.79^{* *}$ & $44.69^{* *}$ \\
LC-1 & $149.46^{* *}$ & $173.35^{* *}$ & $37.79^{* *}$ & $54.00^{* *}$ \\
LC-2 & $174.40^{* *}$ & $197.53^{* *}$ & $36.22^{* *}$ & $48.46^{* *}$ \\
LC-3 & $181.06^{* *}$ & $203.89^{* *}$ & $33.43^{* *}$ & $42.76^{* *}$ \\
LC-4 & $199.23^{* *}$ & $220.94^{* *}$ & $37.25^{* *}$ & $73.37^{* *}$ \\
\hline
\end{tabular}

* significant at p-value $<0.01 * *$ significant at p-value $<0.001$

${ }^{1}$ Multiplicative decomposition model where trend was estimated by loess smoothing 
Since NR is one of the key export oriented primary commodities of the country, the instability in price will bring bad repercussion to the country's economy; especially by creating more uncertainty on foreign exchange funds which is used for the overall development process. Moreover, as indicated by Samarappuli (1993), price instability will affect the employments, producer margins and investments at the micro level. Especially the emerging rubber based industries in the country will be vulnerable to unstable prices discouraging both local and international investors. It is believed that the micro level issue in price instability is more serious due to the associated input demands and spillover effects on the rest of the economy. Sri Lanka has become a price taker as a result of the continuous loss of its market share in the international NR market which is around 1.3\% (IRSG, 2013) which may be the most critical reason for the prevalence of unstable NR prices in the country.

Wijesuriya et al. (1995) has observed that RSS price variations are less compared to the variation in LC prices. However, after the depression in rubber prices experienced during early 2000s, the volatility in RSS1 prices seems to be greater than that of in LC-1X prices (Fig. 3). It can be noticed that this phenomena is similarly reported in the results out of both classes of models fitted to price data. It was observed that this consequence was common in the other RSS grades as well. This situation will bring more issues in the smallholder rubber sector which contributes about $90 \%$ of the total RSS production in the Island. Most of the small holdings belong to the households whose poverty level is at a very low level. Thus immediate actions would need to overcome the instability associated with NR prices; especially with respect to the reforms in the policies relevant to the country's NR sector. Moreover, more research is needed to assess the impact of this issue on the NR sector including the rubber smallholder sector.

\section{Changes in long term trends in NR prices:}

The instability of NR prices in the long run can be regarded as the change in the underlying price trend over the time. If the long term trend is changing frequently, then it will adversely affect the NR industry especially with respect to long run investments and the policy framework. The trend component of the decomposition model and the fitted time series by the stochastic model of RSS1 and LC- $1 \mathrm{X}$ are depicted in Figure 4. 


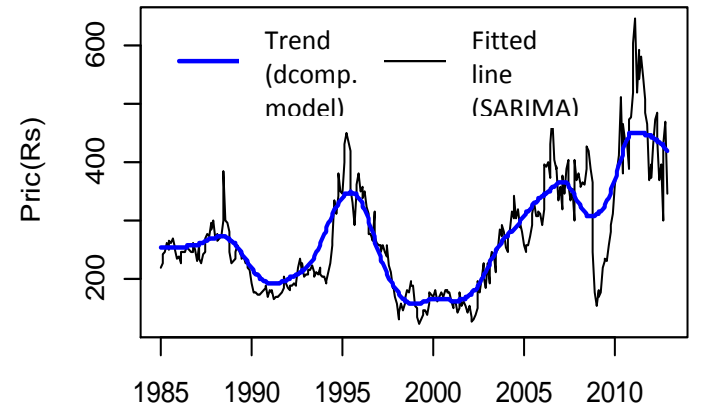

(a) RSS $1 \quad$ Time (Month/Year)

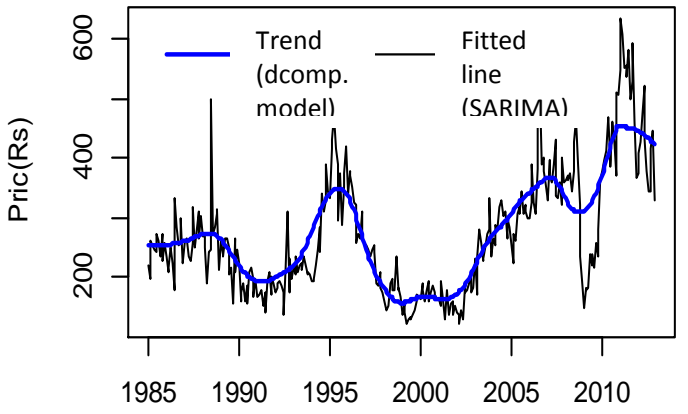

(b) LC-1X Time (Month/Year)

Fig. 4.The trend component of the decomposition model superimposed on the fitted values of the stochastic model; (a) for RSS1 and (b) for LC-1X

Changes occurred in the long term trends of RSS 1 and LC-1X prices are very clearly visible in Figure 4 while a similar pattern was observed with respect to other NR grades. It can be clearly identified the stagnated low NR prices prevailed during late 1990s and early 2000s. Consequently a considerable portion of the rubber plantations has remained untapped and converted into other alternative plantation crops (Wijesuriya et al., 2004).

Seasonality of NR prices:

The seasonal behavior of NR prices in the local market followed by the production cycle is a well-established fact. Wijesuriya \& Thattil (1996) reported the seasonal behavior of average NR auction prices and identified the drop in prices during the high yielding periods. Edirisinghe \& Herath (2004) have reported the same behavior of the prices of LC-1X, Scrap Crepe No $1 \mathrm{Xbr}$ and FOB NR prices at the Colombo market. During this study we confirm the same behavior of prices of RSS grades and other LC grades. Seasonal indices of LC-1X and RSS 1 prices derived using decomposition techniques are presented in Figure 5 which indicates the increase in RSS1 and LC-1X prices during the period where there is a drop in NR production. Moreover, a similar seasonal pattern to what is depicted in Figure 5 was identified with respect to the other NR grades as well. This information is very important for both producers and traders in planning their marketing strategies for higher profit margins. 


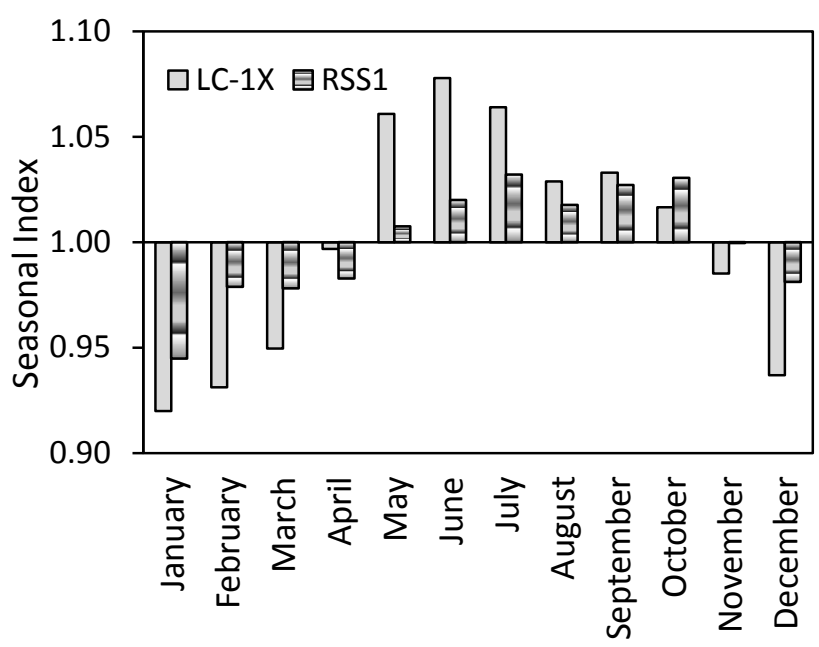

Fig. 5. Seasonal indices of LC-1X and RSS 1 prices resulted from the best fitted decomposition model; a multiplicative model in which trend component bas fitted by loess smoothing

$A C F \mathrm{~s}$ of first order differenced RSS1 and LC-1X prices are depicted in Figure 6 which were similar to the $A C F \mathrm{~s}$ of prices of other RSS and LC grades. Even though some seasonal dependencies of prices are demonstrated in respective $A C F \mathrm{~s}$, the seasonal lengths and respective orders of seasonal AR and MA components are not very evident. However goodness of fit of SARIMA models was greater than the goodness of fit of ordinary ARIMA models fitted to the data. Thus seasonal nature of NR prices cannot be denied. The possible reason for the overwhelmed seasonality may be the high random variability associated with NR prices (Fig. 2). As a result the seasonal pattern observed in Figure 5 can be different at different time frames which can be identified as instability in seasonal variation. This may bring unfavorable consequences to market planning based on seasonal behavior of NR prices. 

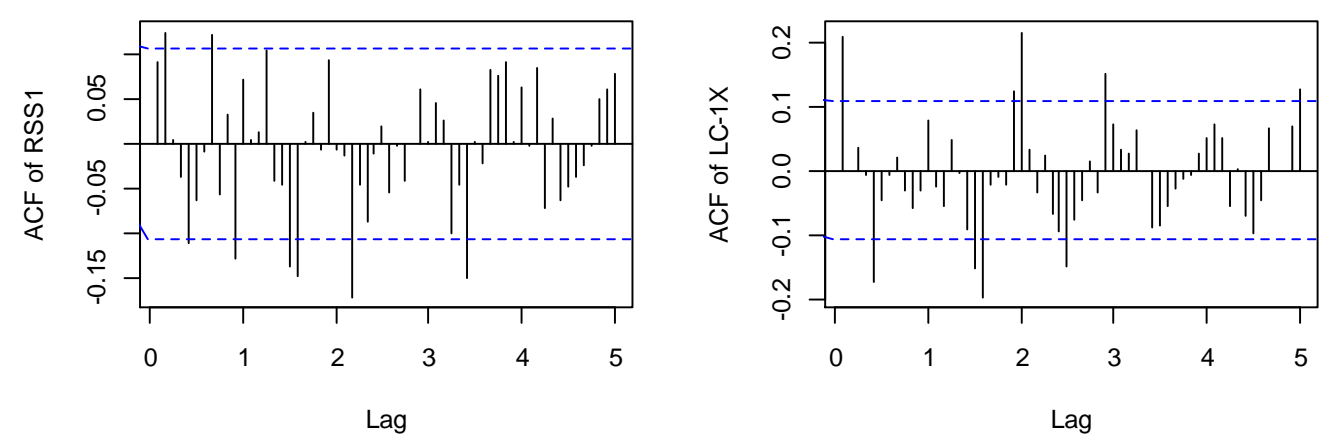

Fig. 6. ACFs of first order differenced prices of RSS1 and LC-1X

\section{Performance of models fitted to NR prices}

During the study it was identified that multiplicative decomposition model was the best fit for NR prices. Out of the different trend fitting methods (linear and polynomials of different orders) loess smoothing was identified as the most efficient method. However, residual analysis revealed that significant amount of ordinary serial dependencies and seasonal effects are left with residuals. It was observed that seasonal variation in the NR prices did not follow the expected systematic pattern in the respective $A C F \mathrm{~s}$ and $P A C F$ s. Thus, the decomposition model was not sufficient enough to model the instable seasonal variations (Fig. 4) and random variations present in NR prices. In the analysis of residuals from SARIMA models, no significant serial dependencies except few ad-hoc serial dependencies were observed in the respective $A C F \mathrm{~s}$ and $P A C F \mathrm{~s}$. Further there weren't any seasonal variations left in the residuals. This indicates that
SARIMA models are more efficient than decomposition models for modeling NR prices. Further, it was noticed that best fitted SARIMA models always reported low MSE, MAE and MAPE values than that of the decomposition models (Table 2).

It is said that SARIMA models can handle some sort of stochastic volatility present in a time series (Shumway and Stoffer, 2006). However this study provides empirical evidence that SARIMA model alone cannot handle the stochastic volatility present in NR prices. But, there are many stochastic volatility models including $\mathrm{ARCH}$ and GARCH models and a wealth of applications available in the time series literature which can handle this sort of volatility present in NR prices. In this study we point out the need of further research addressing the above mentioned issues in time series modeling by applying contemporary time series techniques especially devoted for situations of this nature. 
H M L K Herath et al.

\section{Conclusions}

In conclusion, the instability of NR prices in Sri Lanka is prevailing and persisting. The predominant instability of both RSS and LC prices will be a serious issue to the producers in the smallholder rubber sector and the estate sector. This will directly affect the variability in the producer's margins affecting their cash flow seriously. Since the NR sector is struggling with the increasing labor cost the situation will be more serious. The long term trend in NR prices seems to be frequently changing which can critically affect the policy setup and long run investments in the NR sector. Therefore, the changes in the long term trend in prices should be accounted by the policy makers in the Sector. Since the seasonality of NR prices is overwhelmed by the random shocks in the prices, an extra attention should be paid during the decision making based on the usual pattern of seasonal price variations.

It can be said that recent RSS prices are more unstable compared to the past NR prices in its real terms. This matter should be carefully handled by the policy makers since more than $90 \%$ of the RSS produced in the country are from the rubber smallholder sector in which large number of low and middle income households are engaged in.

As far as the modeling is concerned, it can be concluded that SARIMA models are more efficient in capturing most of the variations in the NR prices. However, we recommend more research which focuses on modeling the aspects of stochastic volatility apparent in NR prices.

\section{References}

Arumugam, P and Anithakumari, V (2013). SARIMA model for natural rubber production in India. International Journal of Computer Trends and Technology 4 (8), 2480-2484.

Bollerslev, T (1986). Generalized autoregressive conditional heteroskedasticity. Journal of Econometrics 31, 307-327.

Box, G E P, Jenkins, G M and Reinsel, G C (1998). Time Series Analysis: Forecasting and Control. $4^{\text {th }}$ edition, John Wiley and Sons Inc., New Jersey.

Chang, C-L, McAleer, M, Tansuchat, R and Khamkaew, T (2010). Modeling conditional correlations in the volatility of Asian rubber spot and futures returns. Mathematics and Computers in Simulation. doi:10.1016/j.matcom.2010.07.004.

Chinye, S and Mesike (2012). Short term forecasting of Nigerian natural rubber export, Wudpecker Journals of Agricultural Research 1 (10), pp. 396400.

Cleveland, R B, Cleveland, W S, McRae, J $\mathrm{E}$ and Terpenning, I (1990). STL: A seasonal-trend decomposition procedure based on loess. Journal of Official Statistics 6, 3-73.

Daud, M N B (1983). Forecasting methodology as applied to rubber prices. Journal of the Rubber Research Institute of Malaysia 31 (3), 188-203.

Dickey, D A and Fuller, W A (1981). Likelihood ratio statistics for autoregressive time series with a unit root. Econometrica 49, 1057-1072. 
Edirisinghe, J C and Herath, H M L K (2004). Seasonal behavior of natural rubber prices in different markets in the world. Bulletin of Rubber Research Institute of Sri Lanka 45, 45-50.

Engle, R F (1982). Autoregressive conditional heteroscedasticity with estimates of the variance of United Kingdom inflation. Econometrica 50, 987-1007.

McLeod, A I and Li, W K (1983). Diagnostic checking ARMA time series models using squared residual autocorrelations. Journal of Time Series Analysis 4, 269-273.

Romprasert, S (2009). Forecasting model of RSS3 prices in future markets. Kasetsart University Journal of Economics 16 (1), 54-74.

Samarappuli, I N (1993). Natural rubber industry: some key economic issues. Bulletin of the Rubber Research Institute of Sri Lanka 30, 11-16.

Shamsudin, M N and Fatimah, M A (1990). Composite model for short term forecasting for natural rubber prices. Pertanika 13(2), 283-288, 43400 UPM Serdang, Selangor DarulEhsan, Malaysia.
Sang, W C, Sriboonchitta, S, Huand, W T and Wiboonpongse, A (2013). Modeling the volatility of rubber price return using VARMA GARCH Model, 財金論文叢 刊, 17, 1-15.

Shumway, R H and Stoffer, D S (2006). Time series analysis and its applications: with R examples. Springer Science + Business Media, New York, USA.

Wijesuriya, Wasana and Thattil, R O (1997). Impact of production, consumption, exports and stocks on the price of natural rubber in Sri Lanka, Journal Rubber Research Institute of Sri Lanka 79, 22-30.

Wijesuriya, B W, Thattil, R O and Samarappuli, I N (1995). Behavior of the natural rubber prices in the Colombo market. $51^{\text {st }}$ Annual Session, SLASS, Colombo.

Address for correspondence: Mr H M L K Herath, Dept. of Agri-Business Management, Faculty of Agriculture and Plantation Management, Wayamba University of Sri Lanka, Makandura, Gonawila (NWP), Sri Lanka.

e-mail: kemindaherath@gmail.com 